\title{
Meta-analysis of Corneal Biomechanical Effects after SMILE and FS-LASIK
}

Jie Qin

Rizhao Central Hospital

Tingting Fu

Hospital Central de La Cruz Roja San Jose y Santa Adela

Qi Tang

Nanchang First People's Hospital

Lu Yang

Rizhao Centre Hospital

Min Chen ( $\square$ minqd@hotmail.com)

Shandong Eye Institute and Qingdao Eye Hospital https://orcid.org/0000-0001-8573-7842

\section{Research article}

Keywords: Small incision lenticule extraction (SMILE), femtosecond laser-assisted in situ keratomileusis (FS-LASIK), biomechanical effects, corneal hysteresis $(\mathrm{CH})$, corneal resistance factor (CRF)

Posted Date: April 12th, 2019

DOI: https://doi.org/10.21203/rs.2.9133/v1

License: (ㅇ (i) This work is licensed under a Creative Commons Attribution 4.0 International License. Read Full License 


\section{Abstract}

Background: To evaluate and compare corneal biomechanics after treatment of myopia using small-incision lenticule extraction (SMILE) and femtosecond laser-assisted in situ keratomileusis (FS-LASIK). Methods: We performed a meta-analysis and searched for reports concerning corneal biomechanics after SMILE and FS-LASIK using MEDLINE, EMbase, CNKI and the Cochrane Library. The analysis included corneal hysteresis (CH) and corneal resistance factor (CRF) before and 3 months after the surgery. The quality of the reports was evaluated using the Newcastle-Ottawa scale (NOS). Statistical analysis was performed using RevMan5. Results: Only six studies with a total of 771 eyes were ultimately included in this meta-analysis, and the random effects model was adopted. The preoperative and three-month postoperative $\mathrm{CH}$ and CRF of SMILE and FS-LASIK were compared by the meta-analysis. No statistically

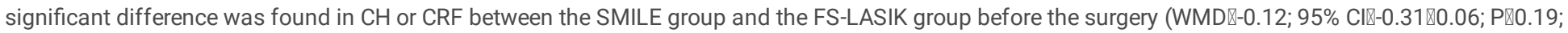
WMD囚-0.05; 95\% Cl囚-0.29凶0.19; Pख0.69). There was no statistically significant difference in $\mathrm{CH}$ between the two surgical methods 3 months after the

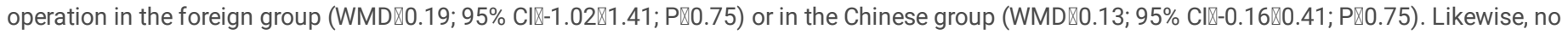
statistically significant difference was found in CRF between the two surgical methods in the foreign group 3 months after the operation (WMD $-0.11 ; 95 \%$ $\mathrm{CI} \bigotimes-2.53 \rrbracket-2.31 ; \mathrm{P} \otimes 0.93$ ). Nevertheless, the difference in CRF between the two surgical methods was statistically significant in the Chinese group (WMD $₫ 0.26$;

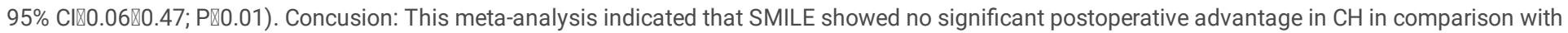
FS-LASIK. For CRF, SMILE exhibited no obvious postoperative advantage in comparison with FS-LASIK in the foreign group, whereas SMILE was superior to FS-LASIK in the Chinese group.

\section{Background}

In recent years, femtosecond laser-assisted in situ keratomileusis (FS-LASIK) and femtosecond laser small incision lenticule extraction (SMILE) have become the mainstream of refractive surgery. Compared with the traditional LASIK, the advantage of FS-LASIK is that the flap creation by femtosecond laser is more precise, thus reducing the occurrence of flap creation complications [1]. SMILE utilizes a femtosecond laser to precisely cut and create a lenticule in the corneal stroma. After mechanical separation, the lenticule is removed without the need for flap creation, therefore minimizing the possible complications associated with flap creation. A large number of studies have also demonstrated the safety and effectiveness of SMILE [2, 3].

Corneal hysteresis $(\mathrm{CH})$ and corneal resistance factor $(\mathrm{CRF})$ are two indicators that reflect corneal biomechanics. $\mathrm{CH}$ reflects the corneal hysteresis, which describes the ability of the cornea to absorb and dissipate energy. CRF includes viscous resistance and elastic resistance, and is an overall reflection of the effects of external force on the cornea. The Ocular Response Analyzer (ORA) is one of the methods to perform corneal biomechanical examinations.

After SMILE and FS-LASIK, the corneal biomechanics declined in comparison with the preoperative conditions [4, 5]. To date, there are multiple clinical studies comparing the superiority of corneal biomechanics after SMILE and FS-LASIK, but the conclusions are not consistent. Therefore, this meta-analysis was conducted in order to quantify the changes of $\mathrm{CH}$ and CRF after SMILE and FS-LASIK. This work compares the stability of corneal biomechanics after the two procedures, and provides guidance on the choice of surgical methods for doctors of corneal refractive surgeries.

\section{Methods}

\section{Inclusion and exclusion criteria}

Studies were considered eligible in accordance with the following criteria: the research reports that may be included in this meta-analysis were prospective studies published between 2011 and July 2018 that investigate the corneal biomechanical effects after SMILE and FS-LASIK. Exclusion criteria: eye or systematic diseases that affect the corneal biomechanical stability, unavailability of data required for statistical analysis, and reprinted articles.

\section{Search strategy}

Two researchers (Qin Jie and Yang Lu) independently performed literature search using the following electronic databases: MEDLINE, Embase, China National Knowledge Infrastructure (CNKI) and the Cochrane Library. A manual bibliography search was also performed. All published and internet accessible articles were considered. If an agreement could not be reached, the matter was discussed with a third researcher. The search period was from 2011 to July 2018. For maximum sensitivity, the search strategies for free text and lexicon terms included "SMILE", "FS-LASIK" and "corneal biomechanics". The literature type was prospective study. There was no language restriction on the publications. This meta-analysis was performed in accordance with the predetermined protocol described in the MOOSE reporting specifications [6, 7].

\section{Data extraction}

Data were extracted from each article using a standardized table: (1) general information: title, author, publication date, resources; (2) results. The six studies included in the meta-analysis provided comparative data suitable for quantitative statistical analysis.

Since the articles eventually retrieved in this work were all cohort studies, they were evaluated using the Newcastle-Ottawa scale (NOS). Articles with scores over 5 points were included in the study. 


\section{Statistical analysis}

The data were analyzed using the RevMan 5 statistical software provided by the Cochrane Collaboration. $\mathrm{CH}$ and $\mathrm{CRF}$ were statistically analyzed by weighted mean difference and $95 \%$ confidence interval. All meta-analyses were heterogeneously assessed using the chi-squared test $\left(\chi^{2}\right)$ and the Q-statistic of the 12 test [8]. 12 estimates the percentage of the total variance in all data that concern heterogeneity. The authors suggest using $25 \%, 50 \%$ and $75 \%$ to represent low, medium and high levels of heterogeneity. The random effects model was adopted due to the small number of articles included in this work. In case of high heterogeneity, a subgroup analysis was performed. The publication bias was assessed using a funnel plot. A P value of less than 0.05 was considered statistically significant $[9,10]$.

\section{Results}

\section{Study characteristics}

A total of 34 potentially relevant articles were identified and screened for retrieval. After a systematic review, only six studies were eventually included in the meta-analysis (Table 1). The six studies were all cohort studies. The progress included in each study is shown in Table 1. Two of the trials were conducted abroad and four were conducted in China. 771 eyes were included in the meta-analysis. Follow-up studies were performed 3 months post-operation. $\mathrm{CH}$ and CRF were the two evaluation indicators assessed in this meta-analysis. The characteristics of each study are listed in Table 1. The process of literature inclusion is illustrated in Figure 1.

\section{Bias evaluation}

The studies included in this work were all cohort studies that were of high quality and had NOS scores greater than 5 . The results of the funnel plot analysis indicated that no significant publication bias existed (Fig. 2).

\section{Meta-analysis results}

\section{CH is an indicator for evaluating corneal biomechanics}

The results indicated that the preoperative heterogeneity between the studies was low $\left(I^{2}=23 \%\right)$. However, due to the small number of articles included, the random effects model was adopted. The difference in $\mathrm{CH}$ between the SMILE group and the FS-LASIK group was not significant (WMD, $-0.12 ; 95 \%$ Cl, -0.31 to $0.06 ; \mathrm{P}, 0.19)$ (Fig. 3). During the three-month follow-up after the operation, the heterogeneity between the studies was large $\left(I^{2}=86 \%\right)$. The random effects model was utilized, and there was no statistically significant difference in CH between the SMILE group and the FS-LASIK group (WMD, 0.17; 95\% Cl, -0.20 to $0.54 ; \mathrm{P}, 0.36$ ). The research subjects of Elmohamdy MN et al. and El-Mayah E et al. were African Egyptians, while the other four articles studied Chinese subjects. Therefore, a subgroup analysis was performed using the random effects model based on ethnicity. The heterogeneities of the SMILE group and the FS-LASIK group in the Chinese subgroup $\left(I^{2}=63 \%\right)$ and the foreign subgroup $\left(I^{2}=83 \%\right)$ decreased, but were still relatively high. In the foreign group, there was no statistically significant difference in postoperative $\mathrm{CH}$ between the two surgical procedures (WMD, $0.19 ; 95 \% \mathrm{Cl},-1.02$ to $1.41 ; \mathrm{P}, 0.75)$. In the Chinese group, there was also no statistically significant difference in postoperative $\mathrm{CH}$ between the two surgical procedures (WMD, 0.13 ; $95 \% \mathrm{Cl}$, -0.16 to $0.41 ;$ P, 0.75) (Fig. 4).

\section{CRF is another indicator for evaluating corneal biomechanics}

The results revealed that the preoperative heterogeneity among the studies was low $\left(I^{2}=45 \%\right)$. The random effects model was adopted due to the small number of articles included. The CRF of the SMILE group and the FS-LASIK group exhibited no statistically significant difference (WMD, $-0.05 ; 95 \%$ Cl, -0.29 to $0.19 ; \mathrm{P}, 0.69)$ (Fig. 5). At the three-month follow-up after the procedure, the heterogeneity among the studies was large $\left(\mathrm{I}^{2}=89 \%\right)$. The random effects model was subsequently applied, and no statistically significant difference was found in CRF between the SMILE group and the FS-LASIK group (WMD, $0.18 ; 95 \% \mathrm{Cl},-0.33$ to $0.69 ; \mathrm{P}, 0.49)$. Subgroup analysis was performed using the random effects models according to ethnicity. The Chinese SMILE and FSLASIK groups showed no heterogeneity $\left(I^{2}=0 \%\right)$, whereas the foreign group exhibited higher heterogeneity $\left(I^{2}=97 \%\right)$. In the foreign group, no statistically significant difference in CRF was found between the two surgical procedures (WMD, $-0.11 ; 95 \% \mathrm{Cl},-2.53$ to $-2.31 ; \mathrm{P}, 0.93$ ). In the Chinese group, a statistically significant difference in CRF was identified between the two surgical procedures (WMD, 0.26; $95 \% \mathrm{Cl}, 0.06$ to $0.47 ; \mathrm{P}, 0.01)$ (Fig. 6).

\section{Complications}


Four out of the six studies explicitly mentioned the absence of complications, while the other two studies stated that both procedures were safe.

\section{Discussion}

Corneal biomechanics will decline after refractive surgeries. In turn, the corneal biomechanical changes result in corneal dilation. Consequently, the changes of corneal biomechanics after refractive surgeries have attracted increasing attention from ophthalmologists. The SMILE procedure does not require flap creation, requires only small incisions, and is free from complications associated with flap creation. Meanwhile, flap creation by FS-LASIK is more precise. Both procedures reduce the corneal thickness, and therefore result in decline of corneal biomechanics. In theory, the SMILE procedure does not generate corneal flaps, does not require cutting of the anterior corneal collagen fibers, uses a femtosecond laser to cut a miniature convex lenticule or convex cylindrical lenticule of a certain size and degree (thickness) at a specific depth in the corneal stroma, and retrieves the lenticule through the small incision around the cornea [11]. Thus, the corneal integrity can be better preserved. The SMILE procedure should provide more stable postoperative corneal biomechanics than FS-LASIK, and is currently regarded as the refractive surgery that brings minimal changes to the postoperative corneal biomechanical properties [12]. However, to date, it remains controversial which of the two procedures enjoy superior corneal biomechanical stability after surgery.

Many researchers have compared the postoperative $\mathrm{CH}$ and CRF between the SMILE and FS-LASIK groups. Two reports by Zhang Jun et al. [13, 14] showed no significant postoperative differences in $\mathrm{CH}$ and CRF between the SMILE group and the FS-LASIK group. However, Wenjing WU et al. [15] and Elmohamady et al. [16] found that $\mathrm{CH}$ and CRF both exhibited postoperative differences between the SMILE group and the FS-LASIK group. Lei Xia et al. [17] and El-Mayah E et al. [18] concluded that while there was no significant difference in the postoperative CH between the SMILE group and the FS-LASIK group, the postoperative CRF was different between the two groups. Therefore, we performed this meta-analysis to clarify whether $\mathrm{CH}$ and $\mathrm{CRF}$ were different after the surgery in the SMILE and FS-LASIK groups.

This meta-analysis indicated that in both the foreign and the Chinese studies, there was no advantage of CH changes in the SMILE group compared with the FS-LASIK group 3 months after surgery. However, even after the subgroup analysis, the heterogeneity between the two subgroups was still high, possibly due to the small number of articles included. Therefore, a meta-analysis with larger sample size is necessary for further validation. In terms of CRF, the SMILE group showed no advantage over the FS-LASIK group 3 months after surgery in the foreign studies, whereas the SMILE group was superior to the FS-LASIK group in the Chinese studies. The decrease in biomechanics is related to the thickness of the corneal cutting, and greater thickness of the FSLASIK corneal cut is correlated with more pronounced changes in CH and CRF $[19,20]$. In addition, the thickness of the corneal cut is related to the preoperative spherical equivalent. For the SMILE surgery, the one-year postoperative corneal biomechanical changes are correlated with the preoperative spherical power of the patients. The higher the degree of myopia, the greater the biomechanical changes of the cornea. The biomechanical changes are also correlated with the sum of preoperative spherical power and cylindrical power. The higher the degrees of myopia and astigmatism, the greater the biomechanical changes of the patients. Moreover, based on our experience, the biomechanical changes exhibit a positive correlation with the thickness of the lens, and thicker lens exerts greater influence on the biomechanics of the cornea. In the Chinese studies, the postoperative CRF of the SMILE procedure was superior to that of the FS-LASIK procedure. This finding may be attributed to the greater degree of myopia and the consequent greater depth of cutting in the Chinese group. One of the six included studies did not record the preoperative central corneal thickness, and two studies did not document the preoperative spherical equivalent. Accordingly, the current meta-analysis was not grouped according to the preoperative spherical equivalent or corneal thickness, and the results may be influence to a certain degree.

Some researchers [19] believe that the thicker the corneal flap created by the femtosecond laser, the greater the alterations of corneal biomechanics. In the FS-LASIK group, the thickness of the flap was $100 \square \mathrm{m}$ in four of the included studies, and the thickness in the other two studies was $90-110 \square \mathrm{m}$ and $100-110$ $\square \mathrm{m}$. A previous report on a pig eye model [21] showed that when the flap thickness was less than $100 \square \mathrm{m}$, there was no significant alteration in $\mathrm{CH}$ or CRF. Therefore, this study did not use grouping by corneal flap thickness. Four of the studies recorded a light zone of $6 \mathrm{~mm}$, while the other two studies did not record the size of the light zone. Thus, the data were not grouped or analyzed by light zone.

There are certain limitations to this study: (1) only a small number of trials were included in this meta-analysis; (2) the observation time was short; (3) the included articles were all cohort studies; (4) we could not obtain unpublished results, and publication bias could be completely ruled out; (5) the patients were not grouped and analyzed based on the preoperative degree of myopia; (6) since there were few articles on the measurement of corneal biomechanics using Corvis ST, this study included the articles on the measurement of corneal biomechanics with ORA. Few biomechanical indicators were included in this study, and only $\mathrm{CH}$ and CRF were measured. This study did not assess corneal deformation parameters, and thus failed to fully reflect the changes in corneal biomechanical properties.

\section{Conclusion}

This meta-analysis systematically analyzed the differences in corneal biomechanics between the SMILE surgery group and the FS-LASIK surgery group. Despite the limitations, we believe that the conclusions derived from this meta-analysis are clinically useful for treatment considerations.

Larger sample size is required to determine whether significant differences in corneal biomechanics exist between the SMILE and FS-LASIK procedures. Multi-center trials and studies with longer follow-ups may be necessary to better evaluate the benefits and safety of the SMILE and FS-LASIK procedures. This work provides insights and guidance on the biomechanical considerations for corneal refractive surgery doctors. 


\section{List Of Abbreviations}

SMILE: Small-incision lenticule extraction; FS-LASIK: Femtosecond laser-assisted in situ keratomileusis; $\mathrm{CH}$ : Corneal hysteresis; CRF: Corneal resistance factor; NOS: Newcastle-Ottawa scale; ORA: Ocular Response Analyzer; CNKI: China National Knowledge Infrastructure.

\section{Declarations}

\section{Ethics approval and consent to participate}

Not applicable

\section{Consent for publication}

Not applicable

\section{Availability of data and material}

All data generated or analyzed during this study are included in this published article.

\section{Competing interests}

The authors declare that they have no competing interests.

\section{Funding}

None

\section{Authors' contributions}

JQ, TTF, QT and LY contributed to the manuscript preparation. JQ and TTF conducted the literature search. JQ and QT contributed to the eligibility assessment of the literature. JQ, TTF, and QT conducted the data extraction process. JQ and LY conducted the meta-analysis and the bias evaluation. JQ, QT and LY contributed to the project design and discussed the results. NL, QS and MC contributed to the proofreading of the manuscript. JQ, TTF, QT, LY and $\mathrm{MC}$ contributed to the revision of the manuscript. All authors have read and approved the manuscript.

\section{Acknowledgement}

We thank Dr. Liu Lei, Associate Professor of Ophthalmology, the First Affiliated Hospital of the China Medical University, member of the Ophthalmology Collaborative Group of the Clinical Epidemiology and Evidence-Based Medicine Branch of the Chinese Medical Association, member of the Asian Eye Epidemiology Commission (AEEC), member of the Asia Pacific Tele-Ophthalmology Society (APTOS), and member of the standing committee of the China Intelligent Ophthalmology Group.

\section{Reference}

1. Li Ying JY. A review of laser corneal refractive surgery. Chin J Optom, Ophthalmol Visual Sci. 2015;17:641-3.

2. Sekundo W, Kunert KS, Blum M. Small incision corneal refractive surgery using the small incision lenticule extraction (SMILE) procedure for the correction of myopia and myopic astigmatism: results of a 6 month prospective study. Br J Ophthalmol. 2011;95:335-9.

3. Vestergaard A, Ivarsen AR, Asp S, Hjortdal JO. Small-incision lenticule extraction for moderate to high myopia: Predictability, safety, and patient satisfaction. J Cataract Refract Surg. 2012;38:2003-10. 
4. Li H, Wang Y, Dou R, Wang L, Xu LL, Li XJ, et al. [Comparison of the effects of different side-cut angles on corneal biomechanical properties after femtosecond laser assisted-laser in situ keratomileusis]. [Zhonghua yan ke za zhi] Chinese journal of ophthalmology. 2017;53:23-32.

5. Chen M, Yu M, Dai J. Comparison of biomechanical effects of small incision lenticule extraction and laser-assisted subepithelial keratomileusis. Acta Ophthalmol. 2016;94:e586-e91.

6. Moher D, Cook DJ, Eastwood S, Olkin I, Rennie D, Stroup DF. Improving the quality of reports of meta-analyses of randomised controlled trials: the QUOROM statement. Quality of Reporting of Meta-analyses. Lancet. 1999;354:1896-900.

7. Stroup DF, Berlin JA, Morton SC, Olkin I, Williamson GD, Rennie D, et al. Meta-analysis of observational studies in epidemiology: a proposal for reporting. Meta-analysis Of Observational Studies in Epidemiology (MOOSE) group. JAMA. 2000;283:2008-12.

8. Higgins JP, Thompson SG, Deeks JJ, Altman DG. Measuring inconsistency in meta-analyses. BMJ. 2003;327:557-60.

9. Mantel N, Haenszel W. Statistical aspects of the analysis of data from retrospective studies of disease. J Natl Cancer Inst. 1959;22:719-48.

10. DerSimonian R, Laird N. Meta-analysis in clinical trials revisited. Contemp Clin Trials. 2015;45:139-45.

11. Zhao J, Ye XU, Zhou XT. Changes in anterior and posterior corneal higher order aberrations after laser in situ keratomileusis with femtosecond VisuMax for high myopia. Chinese Journal of Ophthalmology \& Otorhinolaryngology. 2011.

12. Wu D, Wang Y, Zhang L, Wei S, Tang X. Corneal biomechanical effects: small-incision lenticule extraction versus femtosecond laser-assisted laser in situ keratomileusis. J Cataract Refract Surg. 2014;40:954-62.

13. Zhang J, Zheng L, Tong CS, Xu Y, Chen S, Sun Y. Comparison of the corneal biomechanical effects after small-incision lenticule extraction and Q value guided femtosecond laser-assisted laser in situ keratomileusis. International Eye Science. 2016;16:638-41.

14. Zhang J, Zheng L, Zhao X, Xu Y, Chen S. Corneal biomechanics after small-incision lenticule extraction versus Q-value-guided femtosecond laserassisted in situ keratomileusis. Journal of Current Ophthalmology. 2016;28:181-7.

15. Wu W, Wang Y. The Correlation Analysis between Corneal Biomechanical Properties and the Surgically Induced Corneal High-Order Aberrations after Small Incision Lenticule Extraction and Femtosecond Laser In Situ Keratomileusis. Journal of ophthalmology. 2015;2015:758196.

16. Elmohamady MN, Abdelghaffar W, Daifalla A, Salem T. Evaluation of femtosecond laser in flap and cap creation in corneal refractive surgery for myopia: a 3-year follow-up. Clin Ophthalmol. 2018;12:935-42.

17. Xia L, Zhang J, Wu J, Yu K. Comparison of Corneal Biological Healing After Femtosecond LASIK and Small Incision Lenticule Extraction Procedure. Curr Eye Res. 2016;41:1202-8.

18. El-Mayah E, Anis M, Salem M, Pinero D, Hosny M. Comparison Between Q-Adjusted LASIK and Small-Incision Lenticule Extraction for Correction of Myopia and Myopic Astigmatism. Eye \& contact lens. 2018;44 Suppl 2:S426-S32.

19. Nie XG, Huang YX, He YY, Dong BL. Corneal biomechanics changes after femtosecond laser LASIK surgery. Int Eye Sci. 2018.

20. Li J, Liu JG, Wei SS, Li Y, Wan YQ, Li J, et al. Long-term changes in corneal deformation parameters after laser in situ keratomileusis. Chin J Pract Ophthalmol. 2016;34:231-5.

21. Wang D, Liu M, Chen Y, Zhang X, Xu Y, Wang J, et al. Differences in the corneal biomechanical changes after SMILE and LASIK. J Refract Surg. 2014;30:702-7.

\section{Tables}

Table 1. General information of studies included in the meta-analysis comparing the SMILE and FS-LASIK procedures 


\begin{tabular}{|c|c|c|c|c|c|c|c|c|c|c|}
\hline Title & Author & Journal & $\begin{array}{l}\text { Year, volumn, } \\
\text { page No. }\end{array}$ & Country & Year & Procedure & $\begin{array}{l}\text { Case } \\
\text { No. }\end{array}$ & $\begin{array}{l}\text { Average } \\
\text { age }\end{array}$ & $\begin{array}{l}\text { Study } \\
\text { type }\end{array}$ & $\begin{array}{l}\text { Quality } \\
\text { score }\end{array}$ \\
\hline $\begin{array}{l}\text { 1. Comparison of } \\
\text { the corneal } \\
\text { biomechanical } \\
\text { effects after small- } \\
\text { incision lenticule } \\
\text { extraction and Q } \\
\text { value guided } \\
\text { femtosecond } \\
\text { laser-assisted } \\
\text { laser in } \\
\text { situ keratomileusis }\end{array}$ & $\begin{array}{l}\text { Jun Zhang, } \\
\text { et al }\end{array}$ & $\begin{array}{l}\text { International } \\
\text { Eye Science }\end{array}$ & $\begin{array}{l}2016,16(4): 638- \\
641\end{array}$ & China & 2016 & $\begin{array}{l}\text { SMILE } \\
\text { FS-LASIK }\end{array}$ & $\begin{array}{l}100 \\
100\end{array}$ & $18-40$ & $\begin{array}{l}\text { cohort } \\
\text { study }\end{array}$ & 6 \\
\hline $\begin{array}{l}\text { 2. The Correlation } \\
\text { Analysis between } \\
\text { Corneal } \\
\text { Biomechanical } \\
\text { Properties and the } \\
\text { Surgically Induced } \\
\text { Corneal High-Order } \\
\text { Aberrations after } \\
\text { Small Incision } \\
\text { Lenticule } \\
\text { Extraction and } \\
\text { Femtosecond } \\
\text { Laser In Situ } \\
\text { Keratomileusis }\end{array}$ & $\begin{array}{l}\text { Wenjing Wu, } \\
\text { et al }\end{array}$ & $\begin{array}{l}\text { Journal of } \\
\text { Ophthalmology }\end{array}$ & 2015 & China & 2015 & $\begin{array}{l}\text { SMILE } \\
\text { FS-LASIK }\end{array}$ & $\begin{array}{l}75 \\
75\end{array}$ & $\begin{array}{l}24.25 \pm 5.38 \\
24.28 \pm 5.24\end{array}$ & $\begin{array}{l}\text { cohort } \\
\text { study }\end{array}$ & 6 \\
\hline $\begin{array}{l}\text { 3. Comparison of } \\
\text { Corneal Biological } \\
\text { Healing After } \\
\text { Femtosecond } \\
\text { LASIK and Small } \\
\text { Incision Lenticule } \\
\text { Extraction } \\
\text { Procedure }\end{array}$ & Lei Xia, et al & $\begin{array}{l}\text { Current Eye } \\
\text { Research }\end{array}$ & $\begin{array}{l}2016,41(9): 1202- \\
1208\end{array}$ & China & 2016 & $\begin{array}{l}\text { SMILE } \\
\text { FS-LASIK }\end{array}$ & $\begin{array}{l}64 \\
64\end{array}$ & $\begin{array}{l}25.15 \pm 4.42 \\
23.65 \pm 3.87\end{array}$ & $\begin{array}{l}\text { cohort } \\
\text { study }\end{array}$ & 6 \\
\hline $\begin{array}{l}\text { 4. Corneal } \\
\text { biomechanics } \\
\text { after small- } \\
\text { incision lenticule } \\
\text { extraction versus } \\
\text { Q-value-guided } \\
\text { femtosecond } \\
\text { laser-assisted in } \\
\text { situ } \\
\text { keratomoleusis }\end{array}$ & $\begin{array}{l}\text { Jun Zhang, } \\
\text { et al }\end{array}$ & $\begin{array}{l}\text { Journal of } \\
\text { Current } \\
\text { Ophthalmology }\end{array}$ & 2016,28:181-187 & China & 2016 & $\begin{array}{l}\text { SMILE } \\
\text { FS-LASIK }\end{array}$ & $\begin{array}{l}80 \\
80\end{array}$ & / & $\begin{array}{l}\text { cohort } \\
\text { study }\end{array}$ & 6 \\
\hline $\begin{array}{l}\text { 5. Evaluation of } \\
\text { femtosecond laser } \\
\text { in flap and cap } \\
\text { creation in corneal } \\
\text { refractive surgery } \\
\text { for myopia: a 3- } \\
\text { year follow-up }\end{array}$ & $\begin{array}{l}\text { Elmohamady } \\
\text { MN, et al }\end{array}$ & $\begin{array}{l}\text { Clinical } \\
\text { Ophthalmology }\end{array}$ & $\begin{array}{l}2018: 12 \text { 935- } \\
942\end{array}$ & Egypt & 2018 & $\begin{array}{l}\text { SMILE } \\
\text { FS-LASIK }\end{array}$ & $\begin{array}{l}35 \\
38\end{array}$ & $\begin{array}{l}24.43 \pm 4.91 \\
23.84 \pm 4.75\end{array}$ & $\begin{array}{l}\text { cohort } \\
\text { study }\end{array}$ & 6 \\
\hline $\begin{array}{l}\text { 6. Comparison } \\
\text { Between Q- } \\
\text { Adjusted LASIK } \\
\text { and Small-Incision } \\
\text { Lenticule } \\
\text { Extraction for } \\
\text { Correction of } \\
\text { Myopia and } \\
\text { Myopic } \\
\text { Astigmatism }\end{array}$ & $\begin{array}{l}\text { Esraa El- } \\
\text { Mayah, et al }\end{array}$ & $\begin{array}{l}\text { Eye Contact } \\
\text { Lens }\end{array}$ & 2018 Jul 17 & Egypt & 2018 & $\begin{array}{l}\text { SMILE } \\
\text { FS-LASIK }\end{array}$ & $\begin{array}{l}30 \\
30\end{array}$ & $\begin{array}{l}29.53 \pm 5.37 \\
27.40 \pm 4.95\end{array}$ & $\begin{array}{l}\text { cohort } \\
\text { study }\end{array}$ & 6 \\
\hline
\end{tabular}

\section{Figures}




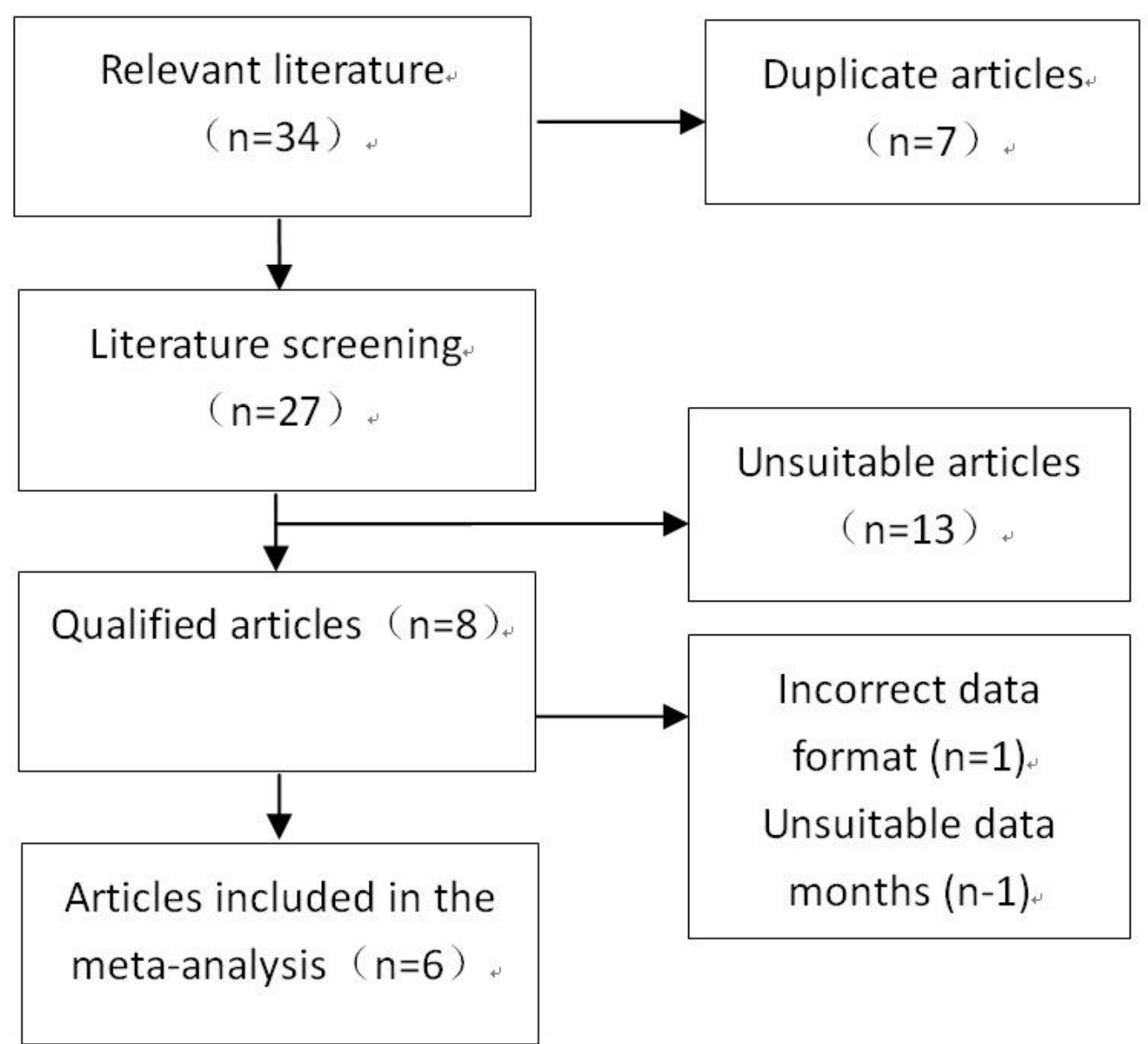

Figure 1

Flow chart demonstrating the process of study inclusion in the meta-analysis.

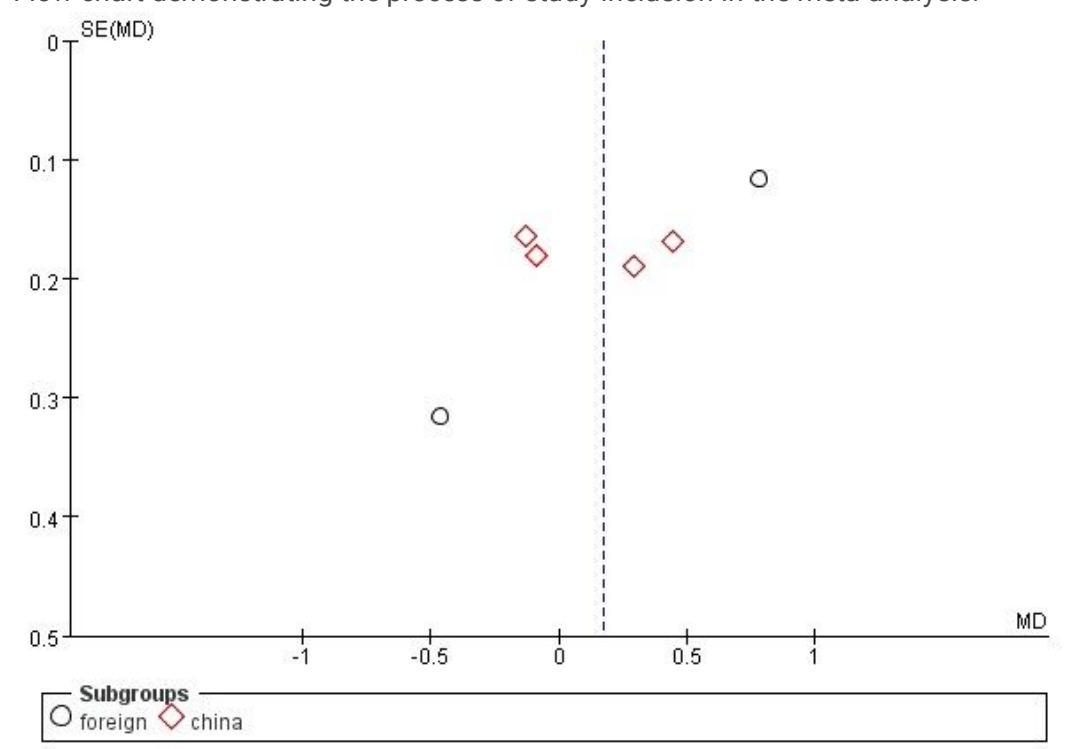

Figure 2

Funnel plot of $\mathrm{CH} 3$ months after the operation. 


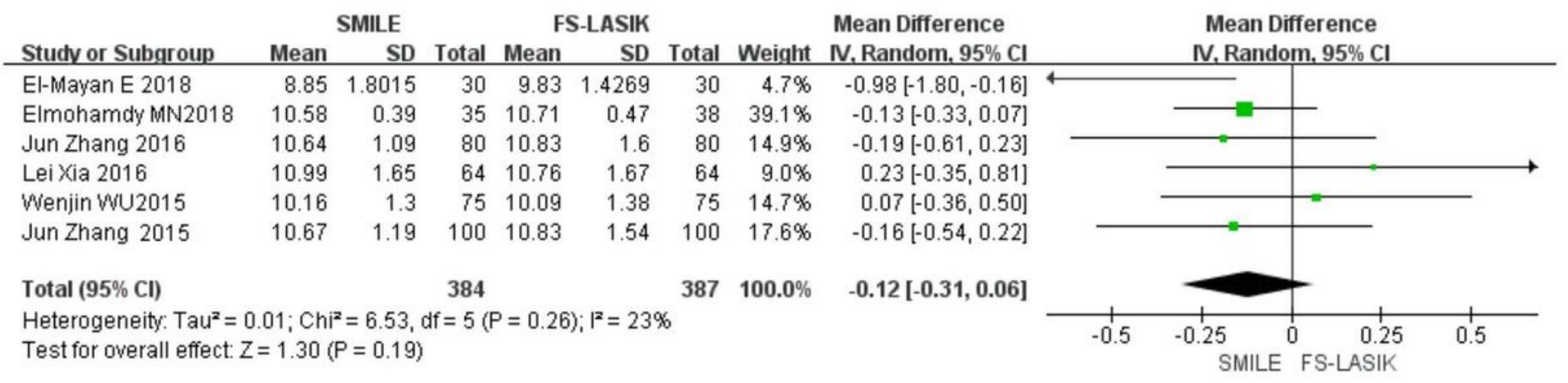

Figure 3

Forest plot displaying the pooled summary estimates of $\mathrm{CH}$ comparing SMILE with FS-LASIK preoperatively. SMILE = small incision lenticule extraction; FSLASIK =femtosecond laser-assisted laser in situ keratomileusis; $\mathrm{CH}=$ corneal hysteresis; IV = weighted mean difference; $\mathrm{SD}=\mathrm{standard}$ deviation; tau2 = tau-square heterogeneity statistic; $\mathrm{Cl}=$ confidence interval; $\mathrm{df}=$ degrees of freedom; $\mathrm{p}=\mathrm{p}$ value; Chi2 = chi-square statistic; $\mathrm{I} 2=\mathrm{I}$-square heterogeneity statistic; Z= Z statistic.

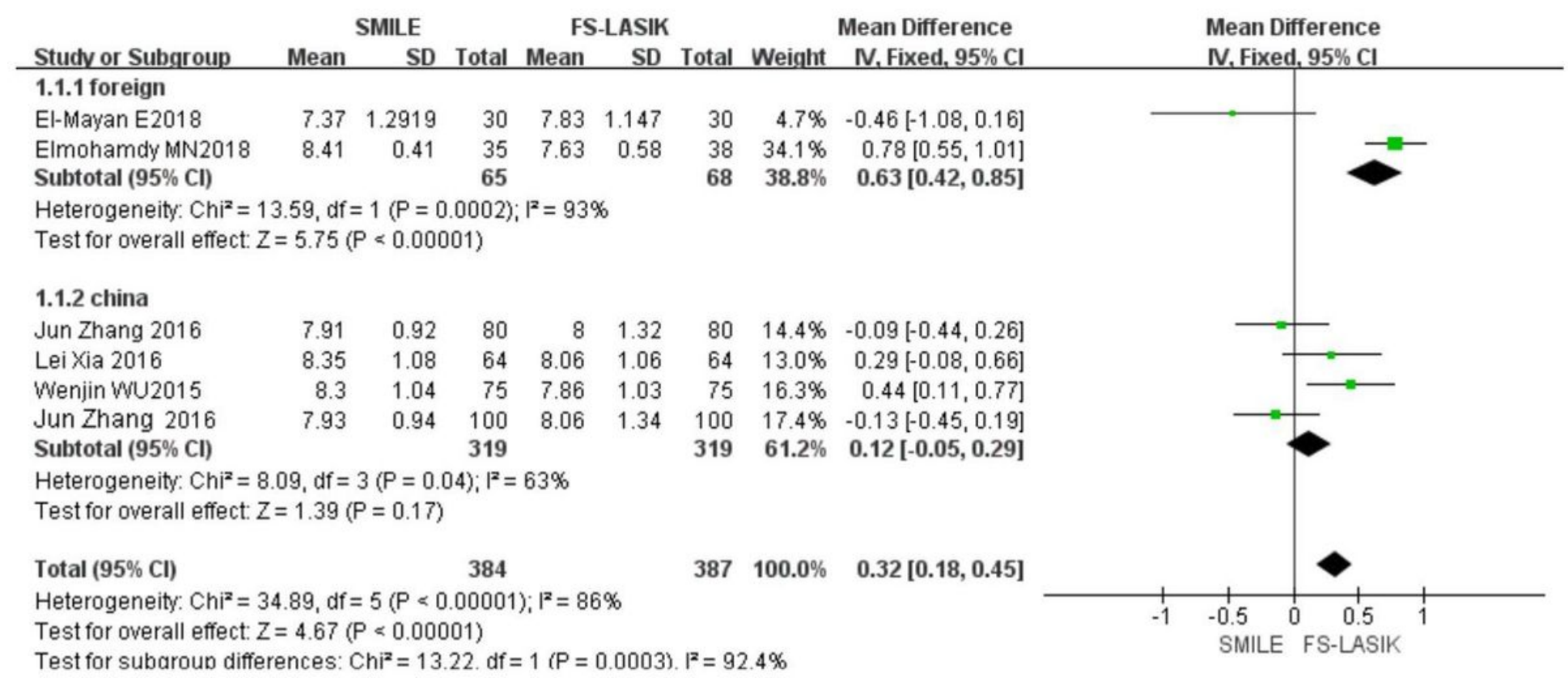

\section{Figure 4}

Forest plot displaying the pooled summary estimates of the subgroup $\mathrm{CH}$ comparing SMILE with FS-LASIK 3 months after the operation. SMILE = small incision lenticule extraction; FS-LASIK = femtosecond laser-assisted laser in situ keratomileusis; $\mathrm{CH}=$ corneal hysteresis; IV = weighted mean difference; SD = standard deviation; $\mathrm{df}$ = degrees of freedom; $\mathrm{p}=\mathrm{p}$ value; $\mathrm{Chi} 2$ = chi-square statistic; $\mathrm{I} 2$ = I-square heterogeneity statistic; $\mathrm{Z}=\mathrm{Z}$ statistic .

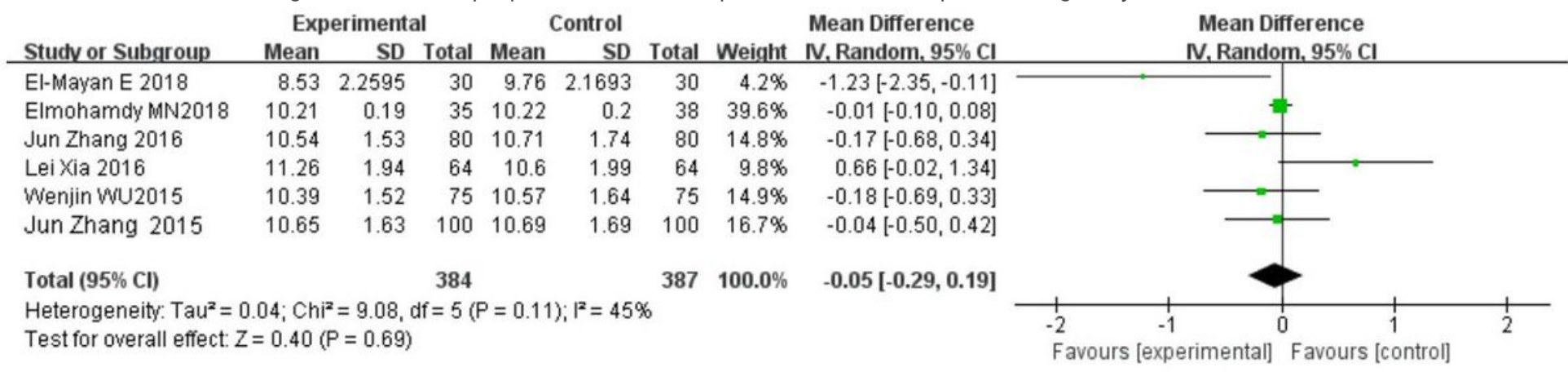

Figure 5

Forest plot displaying the pooled summary estimates of CRF comparing SMILE with FS-LASIK preoperatively. SMILE = small incision lenticule extraction; FS-LASIK = femtosecond laser-assisted laser in situ keratomileusis; CRF = corneal resistance factor; IV = weighted mean difference; SD = standard 
deviation; tau2 = tau-square heterogeneity statistic; $\mathrm{Cl}=$ confidence interval; $\mathrm{df}=$ degrees of freedom; $\mathrm{p}=\mathrm{p}$ value; Chi2 = chi-square statistic; $\mathrm{I} 2=\mathrm{I}$-square heterogeneity statistic; $Z$ = Z statistic.

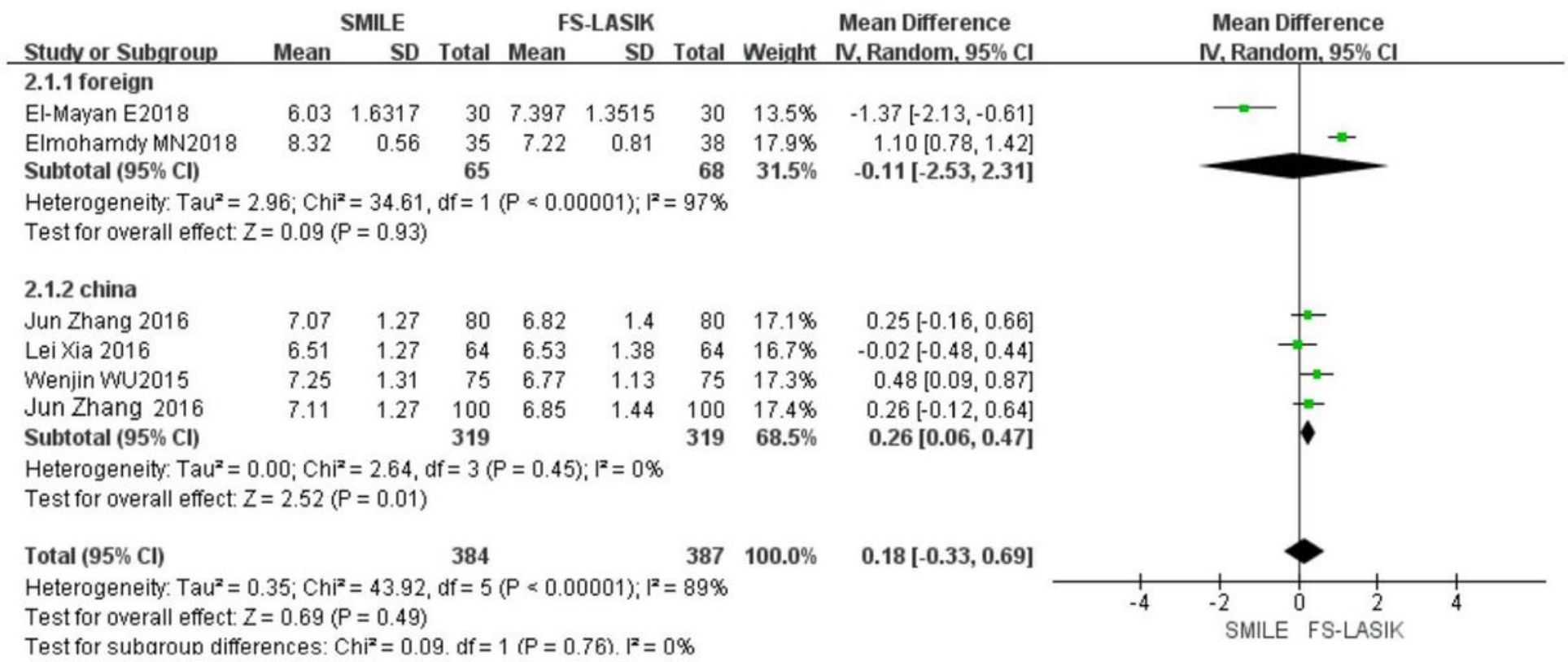

\section{Figure 6}

Forest plot displaying the pooled summary estimates of the subgroup CRH comparing SMILE with FS-LASIK 3 months after the operation. SMILE = small incision lenticule extraction; FS-LASIK = femtosecond laser-assisted laser in situ keratomileusis; CRF = corneal resistance factor; tau2 = tau-square heterogeneity statistic; IV = weighted mean difference; $S D=$ standard deviation; $d f$ = degrees of freedom; $p=p$ value; Chi2 = chi-square statistic; $I 2=I$ square heterogeneity statistic; Z = Z statistic. 